\section{Planejamento urbano, arquitetura e urbanismo: a serviços de uma outra geografia? Brasilmar Ferreira Nunes (em memória)}

\author{
Christiane Girard Ferreira Nunes \\ \& Norma Lacerda*
}

Resumo: O presente artigo trata de um escrito inacabado e inédito de autoria de Brasilmar Ferreira Nunes, falecido em abril de 2016. O objetivo de suas reflexões é mostrar como a nova e íntima associação entre planejamento urbano, urbanismo e arquitetura vem se destacando nas metrópoles, notadamente naquelas do Oriente e Oriente Médio, regiões do globo onde, por razões estratégicas e econômicas, o capitalismo vem se consolidando de forma hegemônica. Ao reconhecer a importante contribuição analítica de Brasilmar Nunes, Christiane Girard introduz o texto, salientando traços da trajetória deste sociólogo que tanto influiu na sua produção acadêmica. Norma Lacerda, por sua vez, finaliza chamando a atenção sobre o ineditismo do artigo e comentando sobre a diversidade de temas por ele abordados.

Palavras-chave: globalização, planejamento urbano, arquitetura, urbanismo

\section{Introdução}

\section{(Christiane Girard Ferreira Nunes)}

1

$m$ dos muitos presentes que Brasilmar Nunes nos ofereceu é o seu interesse em compartilhar as suas análises das complexas cidades atuais, das relações sociais de poder que lá se estabelecem e das formas de resistências a elas. Neste texto inédito que tínhamos, eu e Norma, grande amiga de Brasilmar, consideramos o texto como uma discussão crítica sobre urbanismo, arquitetura, planejamento urbano. Mostra o envolvimento ativo desses setores com a reprodução capitalista, configurando sociedades de mercado. Tecem-se relações, reconfiguram-se espaços na reprodução sempre reinventada de visibilizar espaços de poder, seja ele econômico, de status ou político. É banalidade dizer que a lógica do espaço é apropriada pelo capital, mas é esclarecedor compreender como lógicas de cada campo e território são subjugadas por essa lógica global.

Neste texto, cada um poderá reconhecer a assinatura de Brasilmar Nunes, isto é, as palavras escolhidas com precisão, elegantes e discretas, seu estilo na arquitetura do pensar. Não desvendarei nada de privado dizendo que um de seus sonhos de juventude era tornar-se arquiteto. Na escolha de sua linha de pesquisa, vejo a

\footnotetext{
* Christiane Girard Ferreira Nunes é professora da Universidade de Brasília. <girardchristiane@ gmail.com>.

Norma Lacerda é professora da Universidade Federal de Pernambuco. <norma_lac@yahoo. com.br>.
} 
sua forma de manter, realizar, conciliar esse sonho sendo um estudioso do urbano. Olho para ele e vejo como contra "ventos e tempestades" do percurso de cada um, preservamos o que nos institui, bem como resguardamos o tanto quanto possível a feliz teimosia de tornarmos o que somos. É a partir desse lugar que o acompanho, observando o seu possível lugar de fala na articulação de sua trajetória existencial e coletiva, compartilhando a sua compreensão do Brasil (mesmo se esse artigo trata mais especificamente o tema da globalização).

Fecho os olhos e vejo um jovem cujo os pais mineiros do interior, pequenos produtores rurais, corajosos e sonhadores, se mudam para cidade de tamanho médio do interior paulista. Abrem um estabelecimento comercial. Faltam códigos para operar uma lógica comercial? Passados alguns anos, deverão continuar o processo migratório, recomeçar e continuar a caminhar. Aconteceu isso, talvez, mas não é somente devido às circunstâncias objetivas, há também o desejo de chegar à cidade grande, cada um tem suas razões no grupo familial. Mas migrantes não voltam rumo às primeiras dificuldades, o que se dirá para aqueles que ficaram? São Paulo! São as crianças que realizarão os sonhos dos pais. O capital econômico se esvaiu pelo caminho, mas os filhos poderão estudar e adquirir códigos e estatutos que a geração dos pais não teve acesso. O desenvolvimentismo mostrou que filhos de pequenos produtores rurais podiam esperar passar em concurso do Banco do Brasil ou, quem sabe, ir mais longe ainda! Na grande cidade é possível trabalhar, estudar e até cuidar dos pais. A família se reconfigura. Na migração são os filhos que assumem, em parte, financeiramente o clã, a figura do pai preservada pela mãe simbolicamente continua, são novas contradições próprias à mudança. Não é ainda uma socialização feminista, preservam-se valores tradicionais, mesmo se os lugares e rearranjos modificam as relações familiais. Ainda é implícita. São necessárias adaptações para viver nessa cidade cada vez mais capitalista. Mudança nos papeis da família. A mobilidade social que virá será feita com o esforço do grupo, preservar valores que permitem coesão, mesmo se os filhos se tornam um pouco os pais dos pais. Essa trajetória era sem dúvida existencial, mas moldada pela dinâmica econômica do país. Não posso deixar de pensar sobre os imigrantes na França, sejam eles franceses do interior ou vindo de outras regiões do mundo. Quase sempre os filhos são os tradutores para os pais das regras e leis da cidade grande. Na capital, sem a ajuda do clã seria difícil sobreviver, cada um protege os demais. Nesse exemplo, os pais perdem um estatuto no interior para os filhos ganharem um estatuto na capital. É o que fazem muitos migrantes ao decidirem partir, quando os filhos recebem a injunção de realizar os sonhos dos pais.

Conciliar, ser leal preservando os valores e a história do clã, realizar o sonho dos pais e dos seus exige confrontar-se com muitos desafios e contradições. Brasilmar era 
um urbanista que falava com as plantas e tinha uma grande intimidade com a terra, o cheiro depois da chuva, tipicamente saudoso e triste na lembrança da música do final de tarde aos domingos no interior. Mas convivia na mesma pessoa o urbano absoluto, que prezava em sua necessidade de ser anônimo nas metrópoles. Acompanhava-o a canção de Caetano Veloso "Sampa", que melancólica e prazerosamente sempre cantarolava.

Ele se apaixonou pelo esforço de compreender e compartilhar a leitura dos complexos espaços e territórios, realizou seu desejo de anonimato: foi "flaneur" e "voyeur" em Nova York, Paris e São Paulo. Manifestou sempre seu engajamento para que a cidade preserve seu espaço da Polis. Ser um intelectual engajado foi um valor até o fim de sua vida.

Nunca deixou de ser um mineiro amante do campo, mas também nunca deixou de ser um urbanista apaixonado, fino observador, atento aos muitos movimentos, aceitando os desafios de se reconhecer em alguns. Parece-me que é a forma com a qual aceitamos nossas contradições, a que nos permite caminhar. Ao radicalizarmos um aspecto nosso, o confundimos com a nossa verdade. Somos plurais e contraditórios e talvez seja necessário criar um certo deslocamento interno de questionamento dessas verdades. É também o que faz o intelectual engajado. Analisar a complexidade.

Nessa caminhada, encontro um país tradicional e moderno com rupturas interessantes entre famílias, culturas e trabalho, mas esses aspectos serão objetos de outras leituras. Neste texto, quero lembrar como o Brasil construiu o meu Brasil (perdoem-me o jogo de palavra) e como ele respondeu ao esforço corajoso de ser autor.

Eu amava as suas contradições, obrigado Brasilmar, meu mineiro paulista que desejava ao mesmo tempo viver os últimos tempos de vida no campo, mas também não sair da universidade e voltar a Paris, sempre. Podemos decidir muito pouco talvez e assim também é a vida que decide?

\section{Associação entre o planejamento urbano, a arquitetura e o urbanismo em tempos de globalização (Brasilmar Ferreira Nunes)}

O ser humano é um construtor de cidades. Se voltarmos no tempo, iremos constatar que, uma vez dominadas as técnicas agrícolas, o homem deixa de ser nômade e passa a viver em grupos estabelecidos no território. É quando começam a surgir as primeiras aglomerações, futuras cidades. 
É na aglomeração humana que as práticas de interação se desenvolvem e onde se firmam os princípios do "viver junto", base do fenômeno societário. Embora tenhamos exemplos de cidades no mundo antigo - Egito, Assíria, Mesopotâmia, sem falarmos em antigas cidades asiáticas, ou até mesmo das cidades descritas na Bíblia-, as cidades começaram a se destacar, no Ocidente, a partir da Grécia e do Império Romano, que, em suas respectivas épocas, foram sociedades urbanas. Atenas guarda até hoje a áurea de ter sido uma cidade onde imperavam práticas democráticas e onde a intelectualidade encontrava terreno propício para se manifestar, o que comprova que a sociedade humana encontra nas cidades o ambiente adequado para se firmar. $\mathrm{O}$ Império Romano era urbano. Garantia o domínio de seus territórios conquistados por meio da construção de cidades. Roma, centro do Império, alcançou em seus momentos áureos uma população de mais de um milhão de habitantes. A decadência desse Império coincide com a decadência de Roma e de sua rede de cidades, apontando para um longo período de ostracismo de culturas baseadas em cidades na Europa (Weber, 1967).

Todavia o retorno da centralidade da cidade nas sociedades europeias vai acontecer lentamente, ao longo de séculos, culminando com o aparecimento da indústria, quando o território urbano deixa de ser exclusivamente lugar de troca e de consumo e passa a ser também lugar de produção. Com a indústria, o capital se concentra no território e com ele a população.

Lembremo-nos que sociedades de mercado, naquela época, têm como característica a concorrência entre os agentes econômicos, fenômeno que, por um lado, força a inovação tecnológica na produção e, por outro, induz à expansão do modelo por diferentes contextos, incorporando novos territórios à sua lógica, mesmo quando pressupõe desmontar padrões urbanos preexistentes. Este modelo europeu de sociedade torna-se paradigma para o resto do mundo, consolidando assim o padrão urbano de ocupação do território - guardadas as especificidades locais - que se mantém de até os tempos atuais.

Importa destacar, dentre as diferentes possibilidades de se analisar a cidade, algumas das mais pertinentes, como aquela que considera o território não apenas como o lugar do social, mas ainda fator que participa da geração e reprodução do próprio social. Se assim é, poderíamos nos debruçar sobre a lógica da esfera social em sociedades de mercado e tentarmos delimitar a dinâmica de existência desse social em aglomerações urbanas. Por exemplo, um aspecto recorrente nessas sociedades, e especialmente em cidades, é a profunda lógica de hierarquização dos indivíduos e dos grupos, e que se manifesta em seus territórios. Fenômeno generalizável a praticamente todas as sociedades, a hierarquia - seja na esfera material (econo- 
mia), seja na esfera social (status) ou na esfera política (poder político) - constitui uma tríplice base classificatória de indivíduos e grupos em sociedade, criando então estratos pertinentes a cada esfera. Além do mais, é frequente que essa tríplice hierarquia atue como instrumento de legitimação de profundas desigualdades que, às vezes, são constitutivas de diferentes sociedades. Interessa-nos aqui discernir em que medida tais esferas classificatórias atuam na produção do espaço construído em cidades para, a partir daí, lançar algumas hipóteses sobre a legitimidade que o espaço adquire como instrumento de reforço de tais esferas.

Inicialmente, teríamos que contextualizar o debate, pois não se pode tratar a questão de forma atemporal. Em outras palavras, o sistema social de classificação varia no tempo e no espaço. Se considerarmos o modelo medieval de estrutura urbana, há clara distinção entre a área no interior e no exterior das muralhas que, em geral, cercavam os núcleos urbanos. No caso da América colonial, o padrão urbano foi e continua sendo reflexo da estrutura social, a estabelecer o "centro" como lugar das classes dominantes e suas instituições, sem, no entanto, demarcações rígidas no território entre os diferentes grupos numa espécie de mosaico de padrões econômicos, sociais, culturais e políticos.

Posteriormente, com a hegemonia do mercado, consolida-se o padrão hierarquizado com base no valor da terra, capitaneado pelos interesses imobiliários de então (Igreja, governo, elites urbanas e rurais etc.). Nesse sentido, o modelo classificatório passa a ter no preço da terra o seu fator determinante. Desta maneira, entre os diferentes critérios classificatórios, o território, com suas próprias regras, passa a ser um dos mais recorrentes.

Outro recorte analítico que valeria destacar diz respeito à importância que a cidade vai adquirindo ao longo dos séculos. Lembremo-nos que, como "lugar de mercado", ela sempre exerceu um papel especial na esfera econômica, como lugar de convivência de diferentes grupos com interesses muitas vezes contraditórios. Ao mesmo tempo, Weber (1967) argumenta que, do ponto de vista sociológico, a característica principal da cidade são as relações de vizinhança que nelas ocorrem, justamente em razão da proximidade físico-territorial. O autor se referia aqui às cidades medievais, na medida em que, em sua obra, não há atenção especial às cidades da Era Moderna. Entretanto, o argumento se aplica também à vida em cidades modernas, onde a densidade populacional se torna cada vez mais uma das características recorrentes da vida urbana e a vizinhança permanece sendo também um elemento relevante. Evidentemente essa condição de vizinhança não pressupõe única e exclusivamente relações amigáveis e com densas interações, a noção pode significar também animosidade, desconhecimento, distanciamento (Simmel, 2005), mas pressupõe sempre proximidade física. 
Desde períodos remotos, quando não se tinha ainda o Estado nos moldes atuais, a cidade sintetizava interesses de áreas geográficas restritas ou amplas. A partir do momento em que o Estado-nação se consolida e passa a ser o foco das decisões políticas, a dinâmica das cidades torna-se subordinada ao poder central, perdendo sua autonomia, recuperada com o fenômeno da globalização. A cidade contemporânea (metrópole) amplia o grau de autonomia relativa frente ao próprio Estado. Dessa forma, temos diante de nós, mais uma vez, cidades que desempenham funções próprias para além do controle estatal. Assim, mesmo se levarmos em conta que, nas trocas econômicas, o grau de autonomia das metrópoles contemporâneas é algo costumeiro, é na esfera simbólica que a cidade se torna ícone dos interesses em jogo nas transações internacionais.

Em geral se reconhece que a metropolização é um fenômeno intimamente relacionado à globalização. Com os efeitos concretos dessa nova condição, renovou-se o interesse pelas cidades nesse início de século. O fato é que estamos vivendo um século urbano, com fortes indicações de sua firme consolidação como modelo de ocupação territorial. Nesse sentido, podemos utilizar o argumento de Claude Lacour, segundo o qual

\begin{abstract}
a metropolização é um conjunto de processos privilegiando as grandes dimensões urbanas marcadas pelas transformações do sistema produtivo observadas no nível internacional e mundial. Ela conduz a recomposições territoriais renovadas, tanto no plano interno dos conjuntos urbanos como sobre aquele de suas relações externas (Lacour, 2005: 8).
\end{abstract}

Outro aspecto que merece ser destacado diz respeito ao intenso processo de urbanização/metropolização que vem ocorrendo nas regiões mais pobres do planeta, sobretudo no Hemisfério Sul. Por razões sobretudo relacionadas a fatores de expulsão presentes nas zonas rurais dessas regiões, decorrentes do elevado crescimento demográfico aí observado, levas de migrantes se deslocam e, no geral, se dirigem rumo às grandes aglomerações, generalizando o fenômeno da metropolização, independentemente do grau de desenvolvimento industrial e/ou econômico no sentido amplo. Estamos portanto, diante de um fenômeno universal que se espalhou pelo globo e onde as aglomerações situadas fora do eixo hegemônico do capitalismo apresentam, sistematicamente, um maior crescimento, seja populacional, seja nas atividades econômicas. Continua ainda excessivamente concentrada a geração de riquezas nas áreas metropolitanas históricas que apresentaram elevada competência para se adaptarem aos novos tempos da revolução tecnológica (Sassen, 1991). 
Com essa atual representação nos tempos de globalização, as metrópoles contemporâneas acentuam ainda mais o seu tradicional "lugar de mercado", radicalizando o significado dessa assertiva, até mesmo com a transformação da cidade em mercadoria que se oferece no sistema de troca. Essa lógica ganha importância para certas metrópoles no mundo, tendo relação com o papel que desempenham na dimensão econômica e que se estende para outras esferas do mundo social, tais como a cultural, a política e sobretudo a simbólica. São em geral enormes aglomerações populacionais, marcadas por uma forte presença de indivíduos provenientes de diferentes partes do mundo, a embaralharem os mosaicos que constituem a cidade, criando novas zonas morais, dinamizando a cultura da vida metropolitana, concentrações nas quais, além dessa grande afluência populacional, soma-se ainda o dinamismo de certos segmentos econômicos, que, muitas vezes, comandam setores na esfera mundial.

Se, em sua origem, o urbanismo se consolida a partir da necessidade de procurar soluções ao caos urbano que então se abatia sobre as cidades, sobretudo as principais, nos tempos da globalização ele se firma como disciplina que continua ainda a organizar o crescimento das cidades, mas se coloca também como um dos elementos mais expressivos da transformação do espaço urbano - e da cidade - em mercadoria. Entre a oferta de infraestrutura física para os serviços coletivos - tais como rede viária, transportes, equipamentos de acesso à água e esgoto, iluminação etc. - e os serviços sociais - como educação, saúde, lazer etc. - o urbanismo contemporâneo se consolida como vertente do planejamento urbano, justamente aquele sob a responsabilidade direta ou indireta do Estado. O seu objetivo é adequar e valorizar o espaço físico da cidade, transformando-o em ambiente o mais adequado para se viver, através de diversas intervenções que pode oferecer.

Pois bem, esse quadro caleidoscópico nas metrópoles é também um espaço físico que vem sendo fabricado por indivíduos que o habitam e usam no dia a dia, adaptando-o às expectativas e necessidades rotineiras, onde a originalidade é justamente a dimensão que assume essa produção física da cidade. Nesses novos centros "mundializados", não se pode camuflar a íntima relação que se estabelece entre o urbanismo, a arquitetura e o planejamento urbano, notadamente na parte que se refere à edificação de estruturas para indivíduos privados. Mais ainda, a liberdade que encontram os profissionais da arquitetura e do urbanismo - para "experimentarem" novos usos e formas desses artefatos metropolitanos e do espaço da cidade (Figura 1) - diz respeito tanto às grandes obras de infraestrutura - pontes, avenidas, modernos sistemas de mobilidade etc.) - quanto a construções privadas, tais como edifícios que se apresentam como símbolos econômicos de grandes grupos empresariais ou até mesmo residências particulares que jogam papel importante no sistema de status no meio urbano. 
FIGURA 1

INFINITY TOWER (DUBAI)

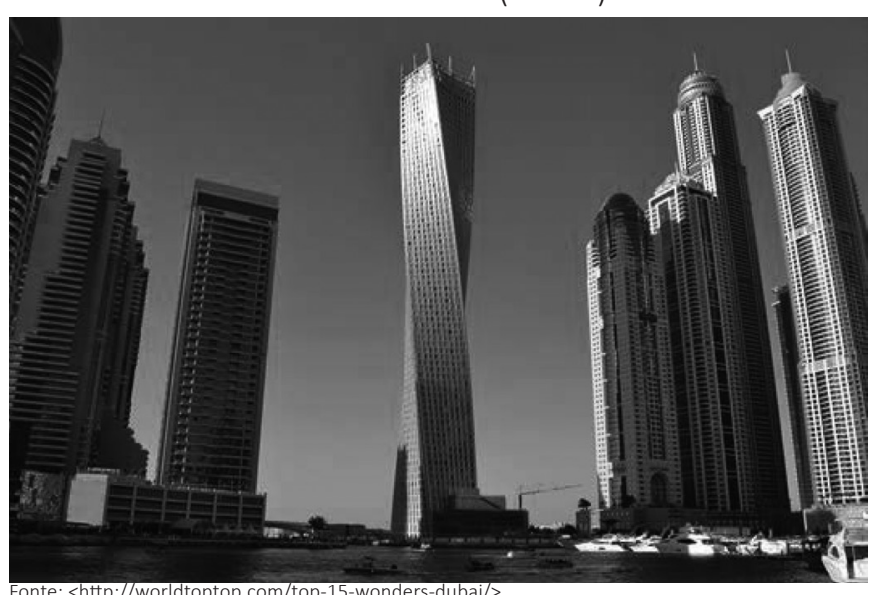

As grandes metrópoles do sistema de mercado já tinham essa estratégia explícita. Nova York, por exemplo, ao longo do século XX, com sua área de Manhattan, expunha a pujança do capitalismo por meio de seus arranha-céus que se apresentavam como símbolos de um capitalismo triunfante. Em menor escala e mais recentemente,

a Avenida Paulista, em São Paulo, também adota esse modelo de expressão das riquezas da cidade (e do país), através de edifícios, muitos com arquitetura arrojada, e que ocupam toda a extensão daquela tradicional avenida da cidade.

FIGURA 2

BURJ KHALIFA (DUBAI)

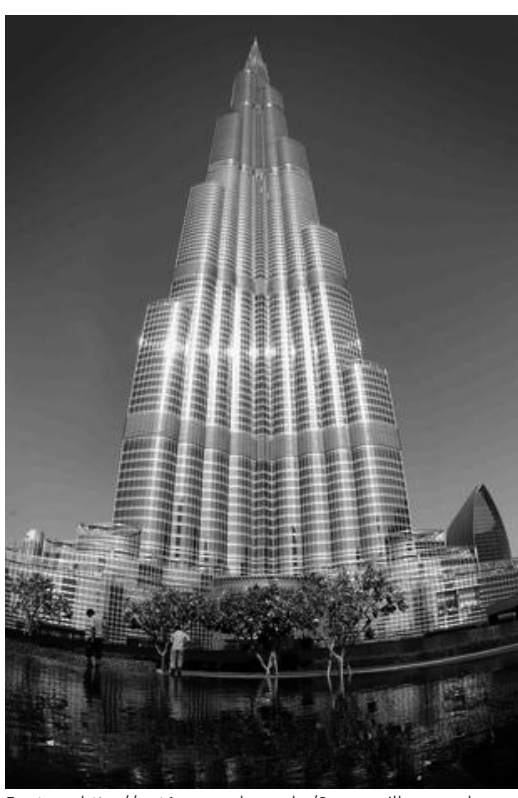

Fonte: <http://not1.xpg.uol.com.br/9-maravithas-modernas -arquitetonicas-oriente-mediofotos-e-informacoes/>.
Sobretudo no último quartel do século passado, foi possível observar um deslocamento do eixo territorial planetário da acumulação do capital em razão da emergência de novos centros do capitalismo. Dessa vez, estendendo-se em direção a países produtores de petróleo (Figuras 2 e 3), e de regiões da Ásia, tendo como principais polos a China, a Coreia do Sul, a Malásia, a Tailândia.

Uma das consequências da globalização é justamente essa expansão do sistema, em sua dimensão mais dinâmica, que repete um modelo territorial preexistente. Ou seja, ali as metrópoles regionais se transformam em grandes centros de irradiação sistêmica, trazendo à baila uma nova concepção de metrópole. Assim, são nesses centros que se expõe a pujança sistêmica, mediante a estreita vinculação do urbanismo com a arquitetura. A adaptação às novas funções mundiais de tais centros vai sendo feita através 
de remodelação físico-territorial das cidades, muitas delas tradicionais centros urbanos nacionais, articulado com a construção de modernos edifícios, com uma arquitetura absolutamente original e arrojada que marca o novo eixo sistêmico. Se no capitalismo, sob a hegemonia norte-americana do século $X X$, tínhamos a síntese do sistema expressa por Manhattan, em Nova York, agora temos múltiplos centros urbanos que se apresentam como novas localidades que Fonte: <http://not1.xpg.uol.com.br/9-maravilhas-modernas arquitetonicas-arquitetonicasse firmam no cenário urbano

mundial, sobretudo pelo estoque de edifícios ultra-arrojados em suas concepções.

Se, por um lado, tais espaços construídos interferem em ritmos e modelos de interação social que ali ocorrem, sendo, portanto, também produtores de sociedade, por outro, dado o porte que adquirem, os aludidos artefatos físicos em tais metrópoles assumem destaques pela dimensão e forma que apresentam.

Essa nova e íntima associação entre planejamento urbano, urbanismo e arquitetura vem se destacando com vigor nas metrópoles do Oriente e Oriente Médio, justamente regiões do globo onde, por razões estratégicas e econômicas, o capitalismo vem se consolidando de forma hegemônica.

Cabe destacar que, desde tempos remotos, a construção de moradias sempre foi alvo de arquitetos. Esses profissionais - sempre preocupados com a estética dos edifícios - construíam palácios, templos e outros prédios com grandes superfícies. Buscavam sempre originalidade no desenho, beleza sensível. Baseavam-se em valores por meio dos quais os seres humanos reconheciam que determinados objetos artísticos ou naturais despertavam universalmente um sentimento de beleza (Sennet, 1997). Ou seja, pelo menos no Ocidente, a arquitetura na cidade sempre foi um território de experimentações artísticas e estéticas.

Outro aspecto que cabe destacar é a dinâmica que o capitalismo adquire nestas últimas décadas e que lhe confere uma nova dimensão em seus mecanismos de 
expansão: a globalização. Um fenômeno que adquiriu, em diferentes níveis - acadêmico, econômico, cultural, entre outros -, unanimidade de analistas. O conceito, no geral, tem relação com o aumento quantitativo e qualitativo de relações sociais, alcançando a escala planetária, implicando em maiores conexões entre as diferentes regiões do globo. Um de seus efeitos é a ressignificação das dimensões do tempo e do espaço, na medida em que acontecimentos locais são induzidos por episódios que ocorrem simultaneamente a enormes distâncias e em outros contextos e reciprocamente. O resultado é que com a globalização as dimensões global, local e cotidiana terminam se interconectando intimamente (Giddens, 2000).

Se retornarmos à dinâmica urbana, iremos nos dar conta de que a globalização alterou o lugar da cidade na dinâmica global, particularmente no lugar ocupado por algumas metrópoles no novo contexto. Atualmente, aumentou a concorrência entre territórios no que se refere à capacidade de atrair investimentos e pessoas, transformando as cidades em "lugares" privilegiados para esta estratégia. Tal "lugar" tem como pré-condição essencial adaptar e ajustar as cidades a fim de adequá-las às necessidades desse novo papel. Aqui, a imagem da cidade desempenha função central. Todo recurso que possa ser utilizado para transformar a cidade em lugar atrativo para investimentos será bem-vindo. O planejamento da cidade estará então voltado a esta dimensão e, consequentemente, acentuado no intuito de envolver a população nesse ideal.

\section{Finalizando: um aceno de despedida}

(Norma Lacerda)

Revisitar esta minuta do artigo escrito pelo amigo Brasilmar Nunes, a mim enviada no final do ano 2014, foi estar com ele, com o seu pensamento, com as suas ideias. Senti, mais do que nunca, a nossa aproximação, a nossa sintonia intelectual. Afinal, sou arquiteta e urbanista. É sobre arquitetura e urbanismo que o texto discorre. Mostra como e o quanto essas duas disciplinas têm servido para a conformação de uma outra geografia urbana mundial.

Importa anotar que elas condensam diferentes arcabouços teóricos norteadores das ações criadoras de espaços construídos. São, portanto, disciplinas de natureza projetual. Sendo assim, os espaços decorrentes dessas ações não se confundem, teoricamente, com os espaços preexistentes, suportes físico-ambientais das ações projetuais, tampouco se confundem com os espaços sociais, essencialmente analíticos, promotores dessas ações (Leitão \& Lacerda, 2016). Brasilmar - cujo sonho, como relembra Christiane na introdução deste texto, era ser arquiteto -, não po- 
deria se furtar a olhar sociologicamente as ações de arquitetos urbanistas, mais especificamente aquelas que estão a serviço do estabelecimento de uma nova organização da urbanização em escala planetária.

É nessa escala que as metrópoles contemporâneas - segundo Brasilmar - assumem "ainda mais o seu tradicional 'lugar de mercado'". Transformam-se em mercadoria, dessa feita, por meio do incremento de meganegócios imobiliários que, na maioria das vezes, significam a destruição de estruturas horizontais de altíssima qualidade ambiental, por estruturas excessivamente verticalizadas. Esses negócios têm, portanto, intensificado o processo de mutação da espacialidade das principais aglomerações urbanas. Considero que aí reside um dos méritos do texto de Brasilmar Nunes: mostrar a funcionalidade da arquitetura e do urbanismo em tempos de globalização, revelar a liberdade dos profissionais dessas disciplinas para experimentarem novas formas e usos desses artefatos metropolitanos, mesmo ao custo da destruição.

Outro mérito ao reencontrar este texto em meus arquivos, especialmente para mim, foi estimular-me a fazer um levantamento de seus escritos. Impressionou-me a abundância de assuntos abordados - sociologicamente, é claro - por Brasilmar (sistema de C\&T, juventude, urbano-rural, mídia eletrônica, práticas espaciais...). Chamou-me particular atenção uma curta matéria (três páginas), veiculada no Jornal do Mauss Iberolatinoamericano com o título "O útil e o necessário: notas sobre crise e sociedade contemporânea", de 2010. Brasilmar expressa de forma perspicaz que a crise da economia capitalista é analisada, sobretudo nos artigos de jornais, como se fosse um mero fenômeno "conjuntural". Chega a ser curioso, como relata,

o fato de que a cada dia é um novo economista - muitos dos quais nunca se tinha ouvido falar, ou lido o que quer que seja - que vem afoitamente a público dar uma interpretação, em geral "a melhor" sobre o fenômeno. O resultado é que a conjuntura cai num emaranhado de subteses e de argumentos que pouco auxiliam na sua compreensão e em uma possível saída. [...] Mais ainda, que a dinâmica do progresso técnico ininterrupto termina gerando o seu próprio abismo. Esse poderia ser um recorte interessante para se refletir sobre o momento atual. Mas tal fato, simples e objetivo, é secundariamente analisado, concentrando-se, sobretudo em grandes falências, concordatas, quebradeiras, desemprego, e tudo o que decorre desse caos na esfera econômico-financeira. Em outras palavras, estamos completamente absorvidos por um fenômeno midiático, onde o que interessa é a notícia bruta e pouco se sabe das reais razões dessa crise. E como sempre a mídia consegue desviar o olhar dos aspectos essenciais, por mais prevenidos que estejamos. 
Sim, é isso que, na maioria das vezes, a mídia faz: desviar o olhar de milhões de espectadores do essencial, da verdade. Isso tem ficado evidente nesses dias tenebrosos vivenciados pelo Brasil, dias envoltos em denúncias de corrupção, mergulhados em uma crise econômica sem precedentes, aguçada pela força desenfreada do capital internacional, ávido por saquear as riquezas brasileiras.

Haveria muito mais para se dizer aqui sobre cidades, crises e economia à luz do pensamento de Brasilmar, ou Brasil, como carinhosamente muitos o chamavam. Ele faz falta em um momento como este que atravessa o país. Sobre isso, cabe uma nota a mais: o filósofo francês Gilles Deleuze, ao falar "amizade" na famosa entrevista conhecida por "Abecedário", comenta que "todas as amizades têm esta base: ser sensível aos signos emitidos por alguém. A partir daí, pode-se passar horas com alguém sem dizer uma palavra ou, de preferência, dizendo coisas totalmente insignificantes". Talvez seja isto que tenha acontecido com este texto de Brasilmar aqui apresentado. Tratava-se de uma conversa, um diálogo entre meu amigo e eu, cuja resposta não consegui dar, talvez porque não fosse mesmo necessário. Tudo já estava posto. Em seu texto que agora vem à luz. Em nossa amizade, que nunca esquecerei.

Abstract: This article is an unpublished and unfinished work written by Brasilmar Ferreira Nunes, who died in April 2016. The purpose of his reflections is to show how the new and intimate association between urban planning, urbanism and architecture has been prominent in the metropolis. Especially those in the East and Middle East, regions of the globe where, for strategic and economic reasons, capitalism has been consolidating in a hegemonic way. Recognizing the important analytical contribution of Brasilmar Nunes, Christiane Girard introduces it, highlighting traces of the trajectory of this sociologist who influenced both his academic production. Norma Lacerda, in turn, ends by drawing attention to the novelty of the text and commenting on the diversity of themes addressed by it.

Keywords: globalization, urban planning, architecture, urbanism.

\section{Referências}

NOVE MARAVILHAS MODERNAS ARQUITETÔNICAS ORIENTE MÉDIO, FOTOS E INFORMAÇÕES. <http://not1.xpg.uol.com.br/9-maravilhas-modernas-arquitetonicas-oriente-mediofotos-e-informacoes>. Acesso: 20 Nov. 2016.

DELEUZE, G. O abecedário de Gilles Deleuze (transcrição integral do vídeo, para fins exclusivamente didáticos). <http://stoa.usp.br/prodsubjeduc/files/262/1015/Abecedario+G.+Deleuze.pdf>. Acessado: 22 Dez. 2016.

GIDDENS, Anthony. O mundo na era da globalização. Lisboa: Presença, 2000. 
INFINITY TOWER DUBAI. <http://worldtoptop.com/top-15-wonders-dubai/> Acesso: 20 Nov. 2016.

JORNAL DO MAUSS IBEROLATINOAMERICANO. <http://www.jornaldomauss.org/jornal/extra/2009_01_20_21_18_43_o_util_e_o_necessario.pdf>. Acesso: 18 Nov. 2016. LACOUR, Claude. Métropolisation et metrópoles: la boussole et le compas. Revista Techni.cités. Paris: Suplément, 23 Nov. 2005.

LEITÃO, L.; LACERDA, N. O espaço na geografia e o espaço da arquitetura: reflexões epistemológicas. Caderno Metrópoles, v. 18, n. 37, p. 803-822. São Paulo, Set.-Dez. 2016.

SASSEN, Saskia. A global city. New York: Paperback, 1991.

SENNET, Richard. Carne e pedra: o corpo e a cidade na civilização ocidental. Rio de Janeiro: Record, 1997

SIMMEL, Georg. As grandes cidades e a vida do espírito. Mana, v. 11, n. 2. Rio de Janeiro, 2005.

WEBER, Max. Conceitos e categorias da cidade. In: VELHO, O. (Org.). O fenômeno urbano. Rio de Janeiro: Zahar, 1967. 